\title{
Case Report: Prostatitis tuberculosis mimicking prostate
}

\section{cancer [version 1; peer review: 2 approved with reservations]}

\section{Syah Mirsya Warli (D), Dhirajaya Dharma Kadar, Muhammad Haritsyah Warli}

Department of Urology, Universitas Sumatera Utara Hospital, Universitas Sumatera Utara, Medan, Indonesia

\author{
V1 First published: 18 Nov 2020, 9:1345 \\ https://doi.org/10.12688/f1000research.26488.1 \\ Latest published: 18 Nov 2020, 9:1345 \\ https://doi.org/10.12688/f1000research.26488.1
}

Open Peer Review
Approval Status ?
Bersion 1
Banda Aceh, Indonesia
Baltimore, USA
Any reports and responses or comments on the
article can be found at the end of the article.

\section{Abstract}

A 56-year-old male who presented with recurrent gross hematuria and moderate lower urinary tract symptoms. After taking the patient's medical history and performing a physical exam, suspicion of prostate cancer arose with prostate enlargement during rectal examination without tenderness and palpable nodes. Ultrasound showed estimated prostate volume of $95 \mathrm{gr}$ and prostate specific antigen of 5.5. Transurethral resection of the prostate was performed and prostate tissue was checked by a pathologist, with histopathological examination showing active tuberculosis lesions. An interferon gamma release assay test was performed, which showed a positive result. The patient was diagnosed with prostatitis tuberculosis and treated with standard nine-month regimen for extra-pulmonary tuberculosis. Prostate enlargement due to tuberculosis is rare and its presence may mimic prostate cancer presentation; however, due to its rarity, careful examination is needed in order to provide optimal management.

\section{Keywords}

Prostatitis, Tuberculosis, Prostate Cancer, Genitourinary Tuberculosis, Prostate Enlargement

\section{Corresponding author: Syah Mirsya Warli (war_uro@yahoo.com)}

Author roles: Warli SM: Conceptualization, Data Curation, Funding Acquisition, Investigation, Supervision, Validation, Writing - Review \& Editing; Kadar DD: Conceptualization, Investigation, Project Administration, Supervision, Writing - Review \& Editing; Warli MH: Formal Analysis, Investigation, Methodology, Visualization, Writing - Original Draft Preparation

Competing interests: No competing interests were disclosed.

Grant information: The author(s) declared that no grants were involved in supporting this work.

Copyright: @ 2020 Warli SM et al. This is an open access article distributed under the terms of the Creative Commons Attribution License , which permits unrestricted use, distribution, and reproduction in any medium, provided the original work is properly cited.

How to cite this article: Warli SM, Kadar DD and Warli MH. Case Report: Prostatitis tuberculosis mimicking prostate cancer [version 1; peer review: 2 approved with reservations] F1000Research 2020, 9:1345 https://doi.org/10.12688/f1000research.26488.1 First published: 18 Nov 2020, 9:1345 https://doi.org/10.12688/f1000research.26488.1 


\section{Introduction}

Tuberculosis (TB) is a chronic condition that is still endemic in Indonesia, with more than 800,000 new cases in 2018. Most cases are primary lung TB $(88 \%)$; however, the genitourinary tract is one of the most common sites of hematogenous spread of extra-pulmonary TB. Genitourinary TB (GUTB), first introduced in 1937 by Wildbolz, is the second most common form of extra-pulmonary $\mathrm{TB}$ in endemic countries ${ }^{1}$. While male genital TB incidence are relatively low, in men, TB may affect the epididymis and the prostate (most common), followed by the seminal vesicles and the testicles ${ }^{1-3}$.

We present the case of a 56-year-old male who presented with recurrent gross hematuria and moderate lower urinary tract symptoms.

\section{Case presentation}

A 56-years-old male presented to the urology clinic with gross hematuria, which had been experienced for the past three months. Hematuria was intermittent and recurrent, with no history of urinary retention or previous trauma. The patient was also experiencing moderate lower urinary tract symptoms (LUTS) with daytime urinary frequency, poor urinary stream, nocturia up to three times a night, straining on bladder emptying and a sensation of incomplete emptying. His International Prostate Symptom Score was 18/35, indicating moderate symptoms, with $4 / 6$ for the quality-of-life component, indicating mostly dissatisfied due to the symptoms. Physical examination was unremarkable, with no other comorbidities and no history of previous surgery. Digital rectal examination was performed, revealing a normal anal tone, normal perianal sensation, but an enlargement of the prostate with a firm consistency and smooth surface. Tenderness and palpable nodes were not found.

Workup was performed, revealing that blood markers were unremarkable with normal renal function, and a prostate specific antigen (PSA) value of $5.5 \mathrm{ng} / \mathrm{dL}$ (normal range, $<4 \mathrm{ng} / \mathrm{dL}$ ). Ultrasound and CT scan revealed prostate enlargement (Figure 1),

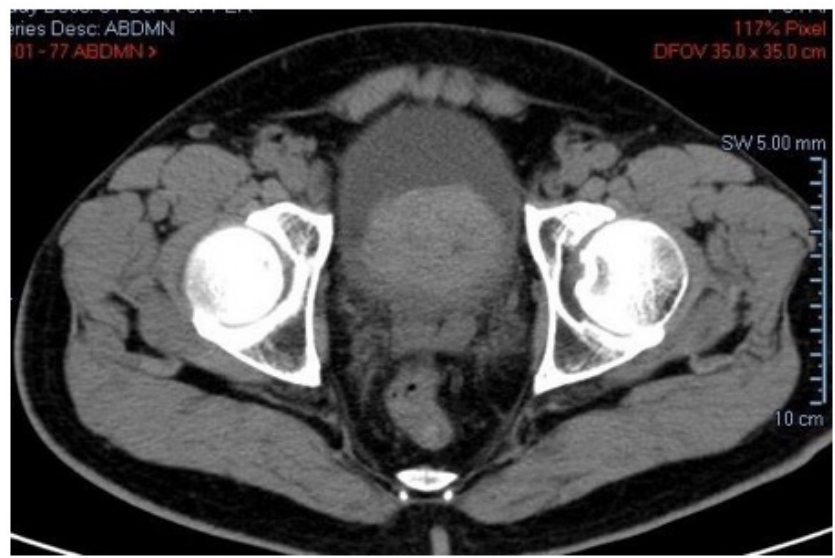

Figure 1. Multi slice computed tomography scan of lower abdomen showing prostate tissue enlargement. with estimated volume of 95 gr. Cystoscopy and transurethral resection of the prostate (TUR-P) were performed for diagnosis as well as therapy to reduce prostate volume. During cystoscopy, the bladder was found to be unremarkable; the bladder wall was normal, with no mass or stone found. The prostate was found enlarged with protrusion to the bladder cavity, and a kissing lobe were found. Resection of the prostate was performed systematically and resected tissue was sent to pathology.

Pathology result showed a typical tuberculosis specimen with tubercles, consisting of epithelioid cells, central necrosis mass accompanied by chronic inflammatory lymphocyte cells, and presence of Langhans type of multinucleated giant cells (Figure 2). Interferon gamma release assay (IGRA) test was then performed to confirm TB diagnosis, which was positive.

The patient was given standard regimen treatment (combination of isoniazid, rifampicin, ethambutol and pyrazinamide for 2 months and isoniazid and rifampicin for the next 7 months) for TB for nine months, with evaluation of symptoms every three months. Evaluation and follow up consisted of history and physical examination, urinalysis and urine cytology and ultrasound of bladder and prostate. After 9 months of oral therapy, an additional CT scan was performed resulting normal prostate image.

\section{Discussion}

TB is a long-term health issue in Indonesia. Current challenges with TB are increased incidence due to drug-resistant cases and HIV spread ${ }^{1}$. One of the most common sites of extra-pulmonary $\mathrm{TB}$ is the genitourinary tract, as it is the primary target of hematogenous infection. The kidney is the most common site of infection in the genitourinary tract. Prostatitis TB is a rare and uncommon presentation of extra-pulmonary tuberculosis. As a type of GUTB, diagnosis of this disease are challenging, as signs and symptoms, such as LUTS and hematuria, may mimic other disorders, such as urinary tract infection, benign prostate hyperplasia, and prostate cancer. Most of the time, diagnosis of prostate TB are incidental, for example made by the pathologist while performing examination of prostate tissue specimen taken from biopsy or prostate resection ${ }^{1,2,4}$. TB in the male genitalia is commonly found in the prostate or epididymal. Some of the most common symptoms are frequent urination, nocturia, dysuria, hematuria, urgency, and hematospermia. On physical examination indurations and nodules on the prostate can be found, which makes it difficult to distinguish from another malignancy; indeed it might be concurrent with other malignancies ${ }^{2,3}$. However, TB in the prostate is often asymptomatic, and has been shown to be found in about $10-14 \%$ of autopsy cases ${ }^{2}$.

Investigation for suspected prostate $\mathrm{TB}$ can be done by examining leukocytes on a three glass urine test, prostate massage secretions, ultrasound examination, and anatomical and cultural pathology examination. The gold standard is biopsy, and confirmation can be done by PCR test ${ }^{3}$. In our case, the patient had moderate LUTS symptoms and hematuria for the last 


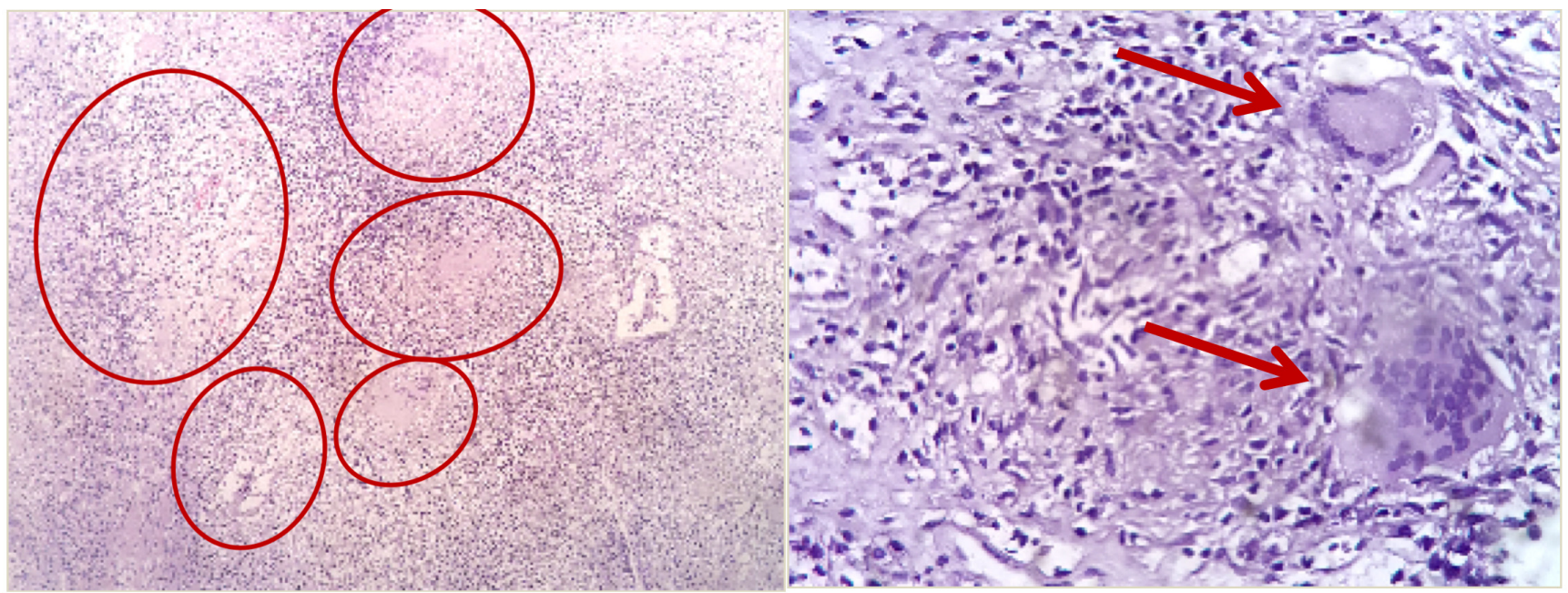

Figure 2. Prostate histopathology taken from TURP procedure.

three months. After examination, an enlargement of the prostate with high PSA value was found. After confirming the enlargement with ultrasound and CT scan, a TUR-P for biopsy was done which returned the result of TB. The positive IGRA test was used for confirmation. The IGRA test cannot be used alone because it will most likely always be positive in an endemic environment for $\mathrm{TB}$, such as Indonesia. An alternative for TB confirmation is PCR.

Management of prostate $\mathrm{TB}$ is the same as other extrapulmonary TB; administration of isoniazid, rifampicin, pyrazinamide and ethambutol or streptomycin every day for two or three months, followed by administration of isoniazid and rifampicin every day for six to seven months (for a total of nine months treatment). In our case, we used a nine month TB drug treatment, with follow-up of the symptoms every three months. Extra-pulmonary tuberculosis including genitourinary TB has a low mortality rate ${ }^{3}$.

\section{Consent}

Written informed consent for publication of their clinical details and clinical images was obtained from the patient.
1. World Health Organization: Global Tuberculosis Report. World Health Organization. 2018. Reference Source

2. Lessnau KD: Tuberculosis of the Genitourinary System. Drug \& Disease Urology. 2019. Reference Source
3. Pringgodigdo, Wahyudi I, Rasyid N: Tuberkulosis Urogenital. Tuberkulosis ekstra paru: Departemen IImu Penyakti Dalam FKUI. 2018; 329-42.

4. Susilawati TN, Larasati R: A recent update of the diagnostic methods for tuberculosis and their applicability in Indonesia: a narrative review. Med Indonesia. 2019; 28: 284-91.

Publisher Full Text 


\section{Open Peer Review}

\section{Current Peer Review Status: ? ?}

\section{Version 1}

Reviewer Report 26 April 2021

https://doi.org/10.5256/f1000research.29245.r82989

(C) 2021 Su Z. This is an open access peer review report distributed under the terms of the Creative Commons Attribution License, which permits unrestricted use, distribution, and reproduction in any medium, provided the original work is properly cited.

\section{Zhuo Tony Su}

Johns Hopkins University, Baltimore, Maryland, USA

The report is well and concisely written and the topic is of interest.

Limited description is available of the patient's past medical, surgical and social history and occupational/environmental exposure.

In the abstract, the authors mentioned that the DRE finding of an enlarged prostate and elevated $\mathrm{BPH}$ prompted a clinical suspicion for prostate cancer, but in the case report, there is no mention of further workup for prostate cancer including prostate biopsy was made before the patient underwent TURP. Please elaborate on the clinical reasoning on the decision to bypass biopsy to TURP.

Please also discuss/elaborate on the following:

What were the patient's urinary symptoms are his post-op follow-up checks? Did any of the urinary symptoms persist and/or recur?

Did the patient experience any systemic symptoms of TB at any point?

Lastly, some epidemiology data on prevalence/incidence of TB in Indonesia and any data on drug resistance in the region would be helpful.

Thanks for the opportunity to review this report.

Is the background of the case's history and progression described in sufficient detail? Partly

Are enough details provided of any physical examination and diagnostic tests, treatment given and outcomes?

Yes 
Is sufficient discussion included of the importance of the findings and their relevance to future understanding of disease processes, diagnosis or treatment?

Partly

Is the case presented with sufficient detail to be useful for other practitioners?

Yes

Competing Interests: No competing interests were disclosed.

Reviewer Expertise: Urology

I confirm that I have read this submission and believe that I have an appropriate level of expertise to confirm that it is of an acceptable scientific standard, however I have significant reservations, as outlined above.

Reviewer Report 18 February 2021

https://doi.org/10.5256/f1000research.29245.r78265

(C) 2021 Dahril D. This is an open access peer review report distributed under the terms of the Creative Commons Attribution License, which permits unrestricted use, distribution, and reproduction in any medium, provided the original work is properly cited.

\section{Dahril Dahril}

Department of Urology, Faculty of Medicine, Dr. Zainoel Abidin General Hospital, Universitas Syiah Kuala, Banda Aceh, Indonesia

1. Pulmonary tuberculosis is the most common and most contagious form of tuberculosis, so if extrapulmonary TB is found, a comprehensive evaluation of the patient suspected of having TB should be done, including clinical history, physical exploration, chest x-ray/CT, and microbiological culture. This may also include a tuberculin test (TST) and serological testing.

2. Extrapulmonary TB (ETB) remains a challenging diagnosis for both clinicians and microbiologists $(7,8)$. Signs and symptoms are most often nonspecific. Obtaining material for culture often requires invasive procedures that cannot be easily repeated. Because of the paucibacillary nature of extrapulmonary specimens and the irregular distribution of bacilli that tend to clump together, the sensitivity of smear microscopy is very low. Cases of ETB are more often culture-negative than cases of pulmonary TB, and when culture is positive, growth on a solid medium may require as long as 8 weeks. Moreover, histopathological findings are not always conclusive.

Is the background of the case's history and progression described in sufficient detail? Yes

Are enough details provided of any physical examination and diagnostic tests, treatment 
given and outcomes?

Partly

Is sufficient discussion included of the importance of the findings and their relevance to future understanding of disease processes, diagnosis or treatment?

Yes

Is the case presented with sufficient detail to be useful for other practitioners?

Partly

Competing Interests: No competing interests were disclosed.

Reviewer Expertise: Clinical and basic of the Urology

I confirm that I have read this submission and believe that I have an appropriate level of expertise to confirm that it is of an acceptable scientific standard, however I have significant reservations, as outlined above.

The benefits of publishing with F1000Research:

- Your article is published within days, with no editorial bias

- You can publish traditional articles, null/negative results, case reports, data notes and more

- The peer review process is transparent and collaborative

- Your article is indexed in PubMed after passing peer review

- Dedicated customer support at every stage

For pre-submission enquiries, contact research@f1000.com

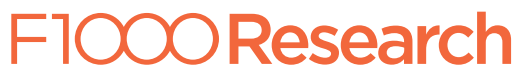

